\title{
Speculation on the possibility
} for introducing Anopheles stephensi as a species complex: preliminary evidence based on odorant binding protein 1 intron I sequence

\author{
Samira Firooziyan ${ }^{1,2}$, Navid Dinparast Djadid ${ }^{3}$ and Saber Gholizadeh ${ }^{1,2^{*}}$ (])
}

\begin{abstract}
Background: Anopheles stephensi is considered an important malaria vector in Iran, Asia, and recently in the Horn of Africa. Recently, Ansteobp 1 intron I sequence has been introduced a new molecular marker for identification of its biological forms including, mysorensis, intermediate and type, using insectary colony specimens.

Methods: In the current study, new marker ability in molecular identification of biological forms has been evaluated with An. stephensi specimens collected from Iran and Afghanistan malarious provinces. Following DNA extraction and PCR amplification, sequence analysis and constructed phylogenetic tree revealed that type and intermediate forms are distributed in Iran.

Results: The specimens collected from Afghanistan identified as intermediate and mysorensis forms. Therefore, intermediate form is sympatric species in both countries. Based on the results of Ansteobp 1 intron I sequences, An. stephensi could be suggested as new Anopheles complex species including An. stephensi sibling A (type form), An. stephensi sibling B (intermediate form) and An. stephensi sibling C (mysorensis form). This is the first report on the presence of An. stephensi biological forms in Afghanistan.

Conclusions: Iran is going to eliminate malaria transmission from the country, precise species identification, especially in complex species will be helpful in the prevention of malaria resurgence in the country, mainly because of common fauna of Anopheles species and through border malaria and population movement within Afghanistan, Pakistan, and Iran.
\end{abstract}

Keywords: Anopheles stephensi complex species, An. stephensi sibling A, An. stephensi sibling B, An. stephensi sibling C

\section{Background}

Anopheles stephensi is one of the approximately 60 Anopheles species considered in malaria transmission as Asian malaria vector $[1,2]$. This species is geographically distributed in South Asia and the Arab Peninsula [3, 4]. Anopheles stephensi is a key vector in malaria transmission not only, in Iran and India, but also in Asia especially in the Persian Gulf area [1, 3, 5-9]. Recently, this species

\footnotetext{
*Correspondence: sabergholizadeh@yahoo.com; saber@umsu.ac.ir

${ }^{2}$ Medical Entomology Department, School of Public Health, Urmia

University of Medical Sciences, Urmia, Iran

Full list of author information is available at the end of the article
}

reported as a malaria vector in the African continent in Djibouti, on the horn of Africa. The high susceptibility of this species to Plasmodium falciparum and its tolerance to urban habitats may challenge the global malaria control and elimination programmes in the future [1].

About one century ago, in 1921, malaria was reported from Iran for the first time [10]. Malaria control intervention was started in 1956 in the country [11]. Now, in the Eastern Mediterranean Region, the malaria control programme is in the elimination phase in Iran and Saudi Arabia, however, transmission is still reported from southeastern parts of Iran [12]. The number of malaria cases in Iran has been decreased from 1847 
(year) to 81 cases in 2016 [13]. The total number of malaria cases until the end of November 2017 was 800 (736 imported and 63 indigenous) (A. Raeisi, pers. comm.).

So far, there are 30 Anopheles species in Iran based on morphological and molecular markers [14], of which four species, including Anopheles maculipennis, Anopheles culicifacies, Anopheles fluviatilis, and Anopheles superpictus, belong to species complex based on ribosomal DNA internal transcribed spacer 2 (rDNA-ITS2) sequences [14-20]. However, despite various studies on An. stephensi, this species was just considered as races or subspecies $[4,14]$. The available information is inadequate to introduce it as a complex species.

A population or series of populations of organisms that are capable of interbreeding freely with each other but not with members of other species is referred to species [21]. There are conflicting reports on crossing experiments between biological or geographical forms of An. stephensi. A definite incompatibility existed in cross-mating between An. stephensi type and mysorensis biological forms [22]. However, intra-specific variation in the reproductive capacity was demonstrated in this species [23]. On the other hand, any hybrid sterility was not found in the crossing between An. stephensi type and mysorensis strains collected from Iran, India, and Iraq [24]. Based on egg morphology characters, An. stephensi has three biological forms including type, intermediate and mysorensis. Distribution of all three forms has been reported from malarious regions in Hormozgan, Sistan-Baluchistan, and Fars provinces of Iran [25]. Recently, by using laboratory reared specimens of An. stephensi, AsteObp1 intron I has been introduced as a new molecular marker for the identification of mysorensis, intermediate and type forms of An. stephensi [4]. In the current study, AsteObp1 intron I was examined as a molecular marker for identification of An. stephensi biological forms on field-collected specimens from the Iran and Afghanistan.

\section{Methods}

\section{Anopheles stephensi mosquitoes}

Mosquitoes were collected form Hormozgan (BandarAbbas district), Sistan and Baluchistan (Chabahar, Nikshahr and Iranshahr districts) and Fars (Kazerun district) provinces in Iran and Nangarhar province (Pole-tarache and Ali Khan villages) in Afghanistan by hand catch collection method in 2015 (Fig. 1). The details of sampling locations were presented in Table 1. Adult $A n$. stephensi specimens were identified morphologically using keys to the adult females and fourth-instar larvae of the mosquitoes of Iran [26].

\section{DNA extraction and PCR amplification}

DNA was extracted from 100 An. stephensi specimens using YTA Genomic DNA Extraction Mini Kit (Yekta Tajhiz Azma, Tehran, Iran). Each mosquito was homogenized in the 200- $\mu \mathrm{l} \mathrm{TG1} \mathrm{buffer} \mathrm{using} \mathrm{a} \mathrm{micropestle.} \mathrm{The} \mathrm{mixture} \mathrm{was}$

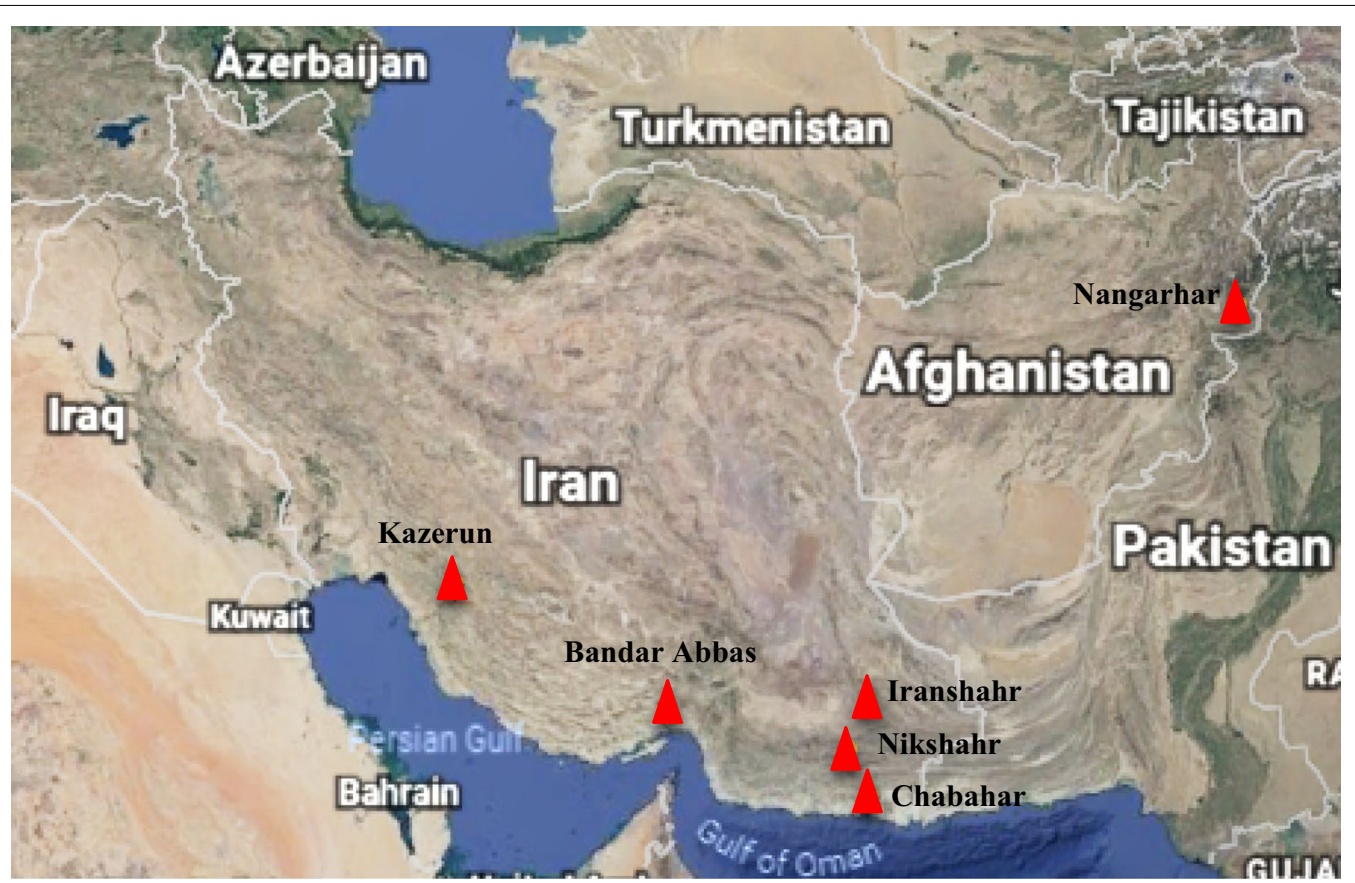

Fig. 1 Collection sites of Anopheles stephensi specimens in Iran and Afghanistan 
Table 1 The details of Anopheles stephensi samples collected from Iran and Afghanistan

\begin{tabular}{llll}
\hline Locations & Latitude $\left({ }^{\circ} \mathrm{N}\right)$ & Longitude $\left({ }^{\circ} \mathrm{E}\right)$ & $\begin{array}{l}\text { Sequenced } \\
\text { specimens }\end{array}$ \\
\hline $\begin{array}{l}\text { Iran } \\
\text { Bandar Abbas }\end{array}$ & $27^{\circ} 11^{\prime} 11^{\prime \prime}$ & $56^{\circ} 15^{\prime} 29^{\prime \prime}$ & $\mathrm{BaU1}, \mathrm{BaU3}$ \\
Chabahar & $25^{\circ} 27^{\prime} 39^{\prime \prime}$ & $60^{\circ} 39^{\prime} 28^{\prime \prime}$ & $\begin{array}{c}\text { ChU1, ChU2, ChU3, } \\
\text { ChU4, ChU5 }\end{array}$ \\
& & & $\mathrm{NiU1}$ \\
Nikshahr & $26^{\circ} 14^{\prime} 14^{\prime \prime}$ & $60^{\circ} 13^{\prime} 46^{\prime \prime}$ & IrU1, IrU3, IrU4 \\
Iranshahr & $27^{\circ} 12^{\prime} 22^{\prime \prime}$ & $60^{\circ} 40^{\prime} 49^{\prime \prime}$ & $\mathrm{KaU3}$ \\
$\begin{array}{l}\text { Kazerun } \\
\text { Afghanistan }\end{array}$ & $29^{\circ} 37^{\prime} 26^{\prime \prime}$ & $51^{\circ} 38^{\prime} 57^{\prime \prime}$ & \\
& & & \\
Nangarhar & $34^{\circ} 26^{\prime} 03^{\prime \prime}$ & $70^{\circ} 26^{\prime} 52^{\prime \prime}$ & $1-\mathrm{H}-\mathrm{H}, 2-\mathrm{H}-\mathrm{H}, 3-\mathrm{H}-$ \\
& & & $\mathrm{H}, 4-\mathrm{H}-\mathrm{H}, 5-\mathrm{H}-\mathrm{H}$ \\
\hline
\end{tabular}

incubated at $60{ }^{\circ} \mathrm{C}$ for $1 \mathrm{~h}$, after the addition of $20-\mu \mathrm{l}$ proteinase K. After incubation, TG2 buffer $(200-\mu l)$ was added and re-incubated for $10 \mathrm{~min}$ at $70^{\circ} \mathrm{C}$. following adding 200$\mu \mathrm{l}$ cold ethanol, the mixture was transferred to TG mini column and centrifuged for $1 \mathrm{~min}$ at $8000 \mathrm{rpm}$. DNA was washed two times with $500-\mu \mathrm{l}$ and $700-\mu \mathrm{l}$ of W1 and wash buffers with a centrifuge for $1 \mathrm{~min}$ at 14,000 rpm, respectively. The DNA was eluted from the column using 100- $\mathrm{ll}$ elution buffer and stored at $-20{ }^{\circ} \mathrm{C}$ until use. The Ansteobp1 intron I region was amplified using OBP1F1 (CGT AGGTGGAATATAGGTGG) as forward and OBP1R1 (TCGGCGTAACCATATTTGC) as reverse primers [4].

PCR reactions of the Ansteobp 1 intron I region were performed in a $25-\mu$ l volume of Master Mix (Yekta Tajhiz Azma, Tehran, Iran). The optimized reactions

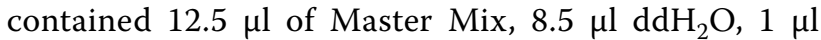
each of specific primers, and $2 \mu \mathrm{l}$ of genomic DNA. The amplification profile was set up with a hot start at $95^{\circ} \mathrm{C}$ for $5 \mathrm{~min}$, followed by 30 cycles of denaturation at $95^{\circ} \mathrm{C}$ for $1 \mathrm{~min}$, annealing at $60{ }^{\circ} \mathrm{C}$ for $1.20 \mathrm{~min}$, and extension at $72{ }^{\circ} \mathrm{C}$ for $1.20 \mathrm{~min}$ with an additional $10 \mathrm{~min}$ extension time in the last cycle. PCR products were visualized on a $0.8 \%$ agarose gel containing safe stain and using a UV transilluminator. The sequencing of amplified fragment in representative samples was performed in an ABI377 automatic sequencer by using the same both amplification primers.

\section{Sequence analysis}

The intron I sequence on An. stephensi Odorant Binding Protein 1 (Ansteobp1) gene was analysed using the Basic Local Alignment Search Tool (BLAST) (http:// www.ncbi.nlm.nih.gov/blast/) and double checked with Chromas software version 2.31 (http://www. technelysium.com.au/chromas.html). The sequences related to different forms of An. stephensi were aligned and compared using Clustal Omega [27]. The final sequences were aligned with three representative sequences in the GenBank. The phylogenetic tree was constructed using distance Neighbor-joining and maximum likelihood Methods based on the TamuraNei model's model in Molecular Evolutionary Genetics Analysis version 6.0. (MEGA6) [28]. Nucleotide sequences are available in the GenBank, European Molecular Biology Laboratory (EMBL), and DNA Data Bank of Japan (DDBJ) databases [GenBank ID: MG797525-MG797537].

\section{Results}

An 845 bp fragment was amplified in 100 field-collected specimens from Iran and Afghanistan using OBP1F1 and OBP1R1 primers [4]. In total, 18 specimens were applied for direct sequencing form Iran $(n=13)$ and Afghanistan $(n=5)$, randomly. The length of intron I region was $115 \mathrm{bp}$ and $120 \mathrm{bp}$ of sequenced specimens. The comparison of these sequences with representative mysorensis [GenBank: KJ557449], intermediate (KJ557452) and type (KJ557463) biological forms intron I sequences showed that Afghani specimens were mysorensis $(n=2)$ and type $(\mathrm{n}=3)$ forms, while Iranian specimens were intermediate $(\mathrm{n}=4)$ and type $(\mathrm{n}=9)$ forms. Therefore, An. stephensi type form was the prevalent biological form in Iranian specimens.

The sequences obtained from An. stephensi specimens collected from Afghanistan were two groups. The sequence similarity within each group was $100 \%$, while it was $86.67 \%$ between both groups. The multiple sequence alignment of KT587049 and KT587051 with representative mysorensis, intermediate and type biological forms showed $99.17 \%$ similarity with mysorensis (KJ557449). A $0.83 \%$ sequence variation was because of a nucleotide transition/transversion $(\mathrm{T} / \mathrm{C})$ in position 81 (Fig. 2). The second group of Afghani sequences, KT587050, KT587052, and KT587053, were a combination of type and intermediate forms. They were $96.67 \%$ similar to representative type form, and $90.43 \%$ to intermediate because of five nucleotide insertion in position 94-99 (Fig. 2). Interestingly, when the phylogenetic tree was constructed, they were placed with intermediate sequences in the same branch (Fig. 3).

The comparison of Iranian field collected An. stephensi Asteobp1 intron I sequence with representative biological forms sequence categorized them into intermediate (BaU3, ChU1, ChU2, and ChU3) and type (BaU1, IrU1, IrU3, KaU3, NiU1, Ch5, Ir4, Ch4, and Ir5) with $100 \%$ similarity. The nucleotide sequence variation between these two forms was $13.04 \%$.

The sequence similarity in Ansteobp 1 intron I region within field-collected specimens of An. stephensi 


\begin{tabular}{|c|c|c|c|c|c|c|c|}
\hline KJ557449tyрет5 & GTGAGCTTGG & GTGTCTTCTG & GATATTGTTC & TAATGTGTTT & TCTGTCTATA & AGTTTTAAAC & 60] \\
\hline MG797525_typeBaU1 & $\ldots \ldots \ldots$ & $\ldots \ldots$ & $\ldots \ldots \ldots$ & $\ldots$ & $\ldots$ & $\ldots \ldots \ldots$ & \\
\hline G797526- typeIrU1 & $\ldots \ldots \ldots$ & & $\ldots$ & & & & $60]$ \\
\hline IG797527_typeIrU3 & & 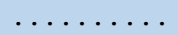 & $\ldots$ & $\ldots$ & & $\ldots$ & [ 60$]$ \\
\hline $7528^{-}$typeKa & $\ldots \ldots \ldots$ & $\cdots$ & $\ldots \ldots$ & $\ldots$ & $\ldots \ldots \ldots \ldots$ & $\ldots \ldots$ & 60] \\
\hline $529-t$ & $\ldots$ & $\ldots$ & $\ldots \ldots$ & $\ldots$ & $\ldots$ & $\ldots \ldots \ldots$ & 60] \\
\hline G797530_typech5 & & & $\ldots$ & & & & [ 60 ] \\
\hline $31^{-}$typeIr4 & 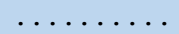 & & $\ldots \ldots$ & & & $\ldots \ldots \ldots$ & [ 60] \\
\hline $32-t$ & $\cdots$ & $\ldots$ & $\ldots \ldots$ & $\ldots \ldots \ldots$ & $\cdots$ & $\ldots \ldots \ldots$ & 60] \\
\hline $3^{-}$ & $\ldots \ldots \ldots$ & $\ldots$ & $\ldots \ldots$ & $\ldots$ & & $\ldots \ldots \ldots$ & $60]$ \\
\hline $53 \overline{\mathrm{A}} \mathrm{f}$ & $\ldots$. & & & & & $\ldots \ldots$ TG & [ 60$]$ \\
\hline an & $\ldots$. & $\ldots$ & $\ldots$ & $\ldots$ & 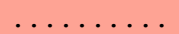 & $\ldots \ldots \mathrm{TG}$. & [ 60 ] \\
\hline$n$ & $\ldots$. & 列 & $\ldots$ & $\ldots \ldots$ & $\cdots \cdots$ & $\ldots \ldots$ TG. & $60]$ \\
\hline $52 i r$ & .... & & & & & $\ldots \ldots \mathrm{TG}$. & [ 60 ] \\
\hline 34 & $\ldots$... & & $\ldots$ & & & $\ldots \ldots$ TG. & [ 60] \\
\hline $5^{-}$ & .... & $\ldots$ & $\ldots$ & . & & $\ldots \ldots$ TG. & [ 60] \\
\hline $5 i$ & $\ldots$. т... & & $\ldots$ & . & & $\ldots \ldots$ TG. & $60]$ \\
\hline $37^{-}$in & $\ldots$. & $\cdots$ & $\ldots$ & $\ldots \ldots \ldots$ & $\ldots \ldots$ & $\ldots \ldots$ TG. & 60] \\
\hline $9 \overline{m i}$ & $\ldots \ldots \ldots$ & . & . . . . & .. & . TAC.... СТ & T.C...TG.. & $60]$ \\
\hline & 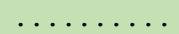 & $\ldots \ldots$ & ...... с . & & . ТАС . . . СТ & T.C...TG.. & $60]$ \\
\hline $51 \mathrm{~A}$ & & & & & . TAC .... CT & T.C...TG.. & 60] \\
\hline & ATCTGG & АСTCTGCATC & ATAA & TGTCA & TGCA & TCA & \\
\hline MG & $\ldots \ldots \ldots$ & $\ldots \ldots \ldots$ & $\ldots$ & $\cdots$ & $\ldots$ & $\ldots$ & $20]$ \\
\hline $6^{-}$ & & & . & . & $\cdots$ & $\ldots \ldots \ldots$ & 120] \\
\hline- & & & & & & $\ldots$ & \\
\hline 8 & $\ldots \ldots \ldots$ & . & .. & . & $\cdots$ & $\ldots \ldots \ldots$ & 0 \\
\hline $9^{-}$ & & & & & & $\ldots \ldots$ & [120] \\
\hline $30 \_t y$ & & & $\ldots$ & & & $\ldots \ldots \ldots$ & [120] \\
\hline 1 & $\ldots$ & ... & $\ldots$ & . & $\ldots$ & $\ldots \ldots \ldots$ & :0] \\
\hline 2 & $\cdots$ & & & & & $\ldots \ldots$ & 20 \\
\hline 33 -t & & & $\ldots \ldots$ & .. & $\ldots \ldots$ & $\ldots \ldots \ldots$ & [120] \\
\hline & & & & .T. & & $\ldots \ldots \ldots$ & {$[120$} \\
\hline & . & & & & & . & 172 \\
\hline 50Afghan & & & & & & & [120] \\
\hline KJ557452interme & & & & . T..---- . & & $\ldots \ldots \ldots$ & [120] \\
\hline & & & & . T..----- & & & {$[120$} \\
\hline 5 & & & & . T..---- & & & 120] \\
\hline 536_interm & & & & .T..---- & & .. & [120] \\
\hline MG797537_inter & & & & . T. .---- & & & {$[120$} \\
\hline $449 \mathrm{my}$ & & . G & $\mathrm{T}$ & .C. & & & \\
\hline & & . G & & & & & {$[12$} \\
\hline KT587051Afghan &.$G \ldots \ldots A$ &. T......G & .1 & .C. & & & [120] \\
\hline
\end{tabular}

Fig. 2 Multiple sequence alignment of Obp1 intron I region of 21 specimens of field-collected specimens of Anopheles stephensi biological forms. Sequences with accession numbers KJ557463 (T5), BaU1, IrU1, IrU3, KaU3, NiU1, Ch5, Ir4, Ch4, Ir5, KT587050, KT587052, and KT587053 are related to An. stephensi type (Blue), KJ557452 (K8), BaU3, ChU1, ChU2 and ChU3 to An. stephensi intermediate (Red), and KJ557449 (B1), KT587049 and KT587051 to An. stephensi mysorensis (Green) forms. A dot indicates identity with the reference sequence and a dash indicates a deletion

biological forms were $100 \%$ but it was $75.65-86.96 \%$ between biological forms. Therefore, neighbor-joining and maximum likelihood phylogenetic trees, constructed based on Ansteobp1 intron I sequence demonstrated a similar topology in type and intermediate branches, while, mysorensis branch was varied in both phylogenetic trees (Fig. 3). Phylogenetic tree constructed based on the maximum-likelihood algorithm in the current study had close proximity with trees constructed in our recent study based on insectary-reared specimens [4].

\section{Discussion}

Among three biological forms of An. stephensi, the majority of malaria transmission was carried out by type form in its range [3]. Recently, the genome of the Indian strain of An. stephensi was analysed [2]. In addition, the distribution and possible role of this major urban malaria vector in the resurgence of malaria in Africa have been reported [1]. The form of collected An. stephensi strain from the horn of Africa is not clear, however, it could be suggested that they can use Ansteobp1 intron I sequence to determine it, which will be helpful in rapid interruption of malaria transmission cycle in the region and complete eradication of $A n$. stephensi from African countries.

All of three biological forms of An. stephensi have been distributed in malarious provinces of Iran including Sistan and Baluchistan, Hormozgan and Fars [25]. In the current study, An. stephensi specimens collected from Iranshahr (Sistan and Baluchistan province) and Kazerun (Fars province) were determined as type (An. stephensi sibling A), while, Bandar-Abbas (Hormozgan province) and Chabahar (Sistan and Baluchistan province) 


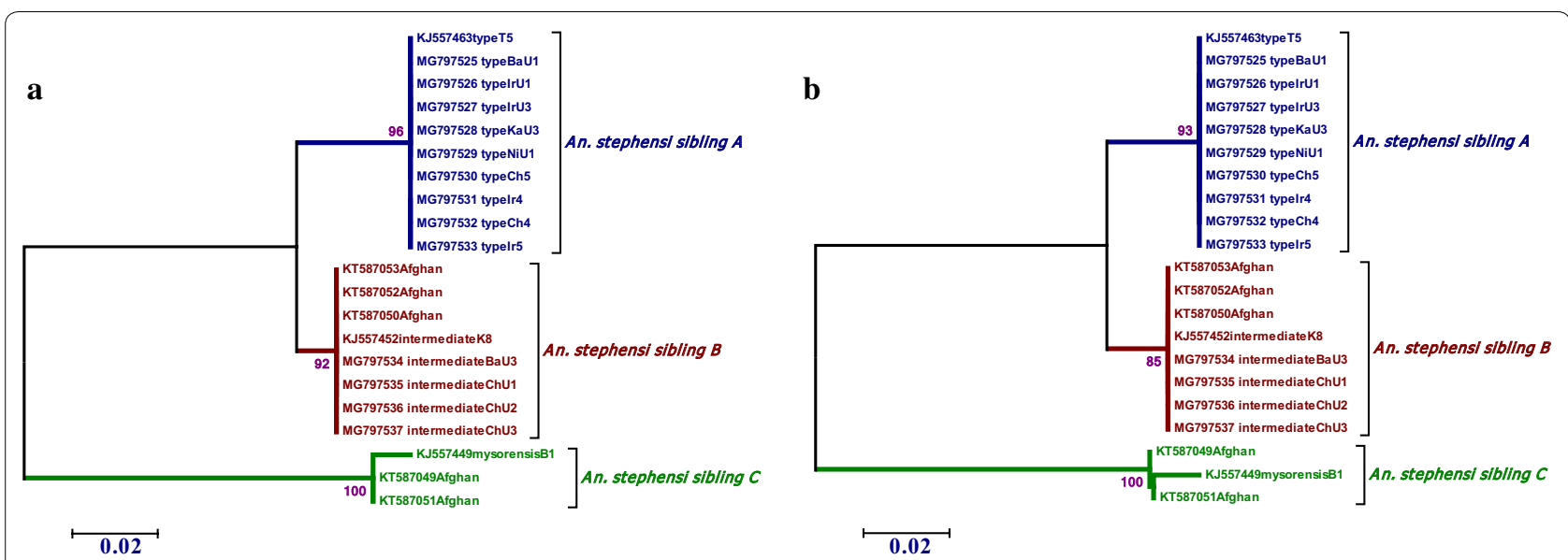

Fig. 3 Maximum likelihood (a) and neighbor-joining (b) phylogenetic trees based on AnsteObp1 intron I fragments for Anopheles stephensi specimens collected from Iran and Afghanistan. The bootstrap consensus tree inferred from 1000 replicates is taken to represent the evolutionary history of the taxa analyzed. Bootstrap values $>50 \%$ has been shown above each node. All positions containing gaps and missing data were eliminated from the dataset (complete deletion option). GenBank ID: KJ5574449, KJ557452, and KJ557463 were used as representative sequences for An. stephensi mysorensis, intermediate and type biological forms Obp1 intron I sequence [4]

specimens were both type (An. stephensi sibling $\mathrm{A})$ and intermediate (An. stephensi sibling B) forms. The intermediate (An. stephensi sibling B) and mysorensis (An. stephensi sibling $C$ ) were the forms collected from Nangarhar province in Afghanistan. Therefore, the distribution of intermediate form (An. stephensi sibling B) was reported in both countries, Iran and Afghanistan.

Anopheles stephensi was classified into two variety based on the number of egg ridges in 1937 [29]. Since these numbers have extensive overlap in intermediate form, it may not be possible to detect forms accurately; therefore, the cross may occur between the same biological forms. This hypothesis may be the reason for conflicting results in crossing experiments. Therefore, it is recommended that cross-experiments be performed after accurate identification of the forms with molecular markers, such as obp1 intron I. Earlier, various studies used chromosomal karyotypes in differentiation between the rural and urban population of An. stephensi [30-32]. They reported that rural and urban populations of this species are different races.

The precise identification of Anopheles species is very important in malaria surveillance, control, and elimination programs. Mitochondrial and DNA-based methods were used to identification of An. stephensi, Anopheles culicifacies, Anopheles superpictus, Anopheles maculipennis, Anopheles fluviatilis, Anopheles sacharovi, Anopheles dthali, and Anopheles pulcherrimus species reported as malaria vectors in Iran, based on rDNA-ITS2 sequence, however, An. maculipennis, An. culicifacies and An. fluviatilis belong to complex species [15-17, 33, 34]. Recently, An. superpictus introduced a suspected cryptic species complex, based on molecular phylogenetic analysis of
Iranian anophelines $[14,20]$. In addition, An. stephensi still under genetic dissociation within its different biological forms including, type, Intermediate and mysorensis, and is considered as a suspected cryptic species complex. ITS2 and D3 loci showed identical nucleotide sequences in type and mysorensis biological forms suggested that these molecular markers are not suitable for the identification of biological forms [35]. On the other hand, Anopheles persiensis was characterized and named principally as a new record to the world and Iranian Anopheles fauna based on DNA evidence for the first time [36] without any crossing experiment between An. maculipennis complex members. These markers seem not to be the proper markers for isolating and identifying the biological forms of this species. However, it was shown that three biological forms of An. stephensi insectary strains could be easily determined using Ansteobp1 intron I sequence [4]. In the current study, the idea was examined using field-collected An. stephensi specimens from Sistan and Baluchistan, Hormozgan and Fars provinces in Iran and Nangarhar province in Afghanistan. Sequence analysis confirms that Ansteobp1 intron I sequence could be introduced as a molecular marker for the detection of three biological forms (Fig. 3). Therefore, An. stephensi could be considered as complex species including An. stephensi sibling A (type), An. stephensi sibling B (intermediate) and An. stephensi sibling $\mathrm{C}$ (mysorensis).

\section{Conclusions}

The current study reports mysorensis and intermediated biological forms of An. stephensi in Afghanistan for the first time. The distribution pattern of the biological form 
using a new molecular marker with field specimens is not compatible with their distribution based on egg morphology. It seems that An. stephensi could be assumed as new malaria vector complex species and should be considered in malaria control and elimination programmes.

\section{Abbreviations}

rDNA-ITS2: ribosomal DNA internal transcribed spacer 2; Ansteobp 1: An. stephensi odorant binding protein 1; BLAST: Basic Local Alignment Search Tool; MEGA6: Molecular Evolutionary Genetics Analysis version 6.0; EMBL: European Molecular Biology Laboratory; DDBJ: DNA Data Bank of Japan.

\section{Authors' contributions}

Conceived and designed the experiments: SG and SF. Performed the experiments: SF and NDD. Analyzed the data: SG. Contributed reagents/materials/ analysis tools: SG and NDD. Wrote the paper: SG, NDD, and SF. All authors read and approved the final manuscript.

\section{Author details}

${ }^{1}$ Cellular and Molecular Research Center, Urmia University of Medical Sciences, Urmia, P.O. Box: 5756115198, Iran. ${ }^{2}$ Medical Entomology Department, School of Public Health, Urmia University of Medical Sciences, Urmia, Iran. ${ }^{3}$ Malaria and Vector Research Group, National Insectarium, Pasteur Institute of Iran, Tehran, Iran.

\section{Acknowledgements}

This study was supported by the Iranian Ministry of Health and Cellular and Molecular Research Center, Urmia University of Medical Sciences, Urmia, Iran (Number 1393-04-43-1610).

\section{Competing interests}

The authors declare that they have no competing interests.

\section{Availability of data and materials}

Data supporting of this article are included within the article and additional file.

\section{Consent for publication}

Not applicable.

\section{Ethics approval and consent to participate}

Not applicable.

\section{Funding}

This study was supported by the Iranian Ministry of Health and Cellular and Molecular Research Center, Urmia University of Medical Sciences, Urmia, Iran (Number 1393-04-43-1610).

\section{Publisher's Note}

Springer Nature remains neutral with regard to jurisdictional claims in published maps and institutional affiliations.

Received: 4 March 2018 Accepted: 9 October 2018 Published online: 16 October 2018

\section{References}

1. Faulde MK, Rueda LM, Khaireh BA. First record of the Asian malaria vector Anopheles stephensi and its possible role in the resurgence of malaria in Djibouti, Horn of Africa. Acta Trop. 2014;139:39-43.

2. Jiang $X$, Peery A, Hall AB, Sharma A, Chen X-G, Waterhouse RM, et al. Genome analysis of a major urban malaria vector mosquito, Anopheles stephensi. Genome Biol. 2014;15:459.

3. Gakhar SK, Sharma R, Sharma A. Population genetic structure of malaria vector Anopheles stephensi Liston (Diptera: Culicidae). Indian J Exp Biol. 2013;51:273-9.
4. Gholizadeh S, Firooziyan S, Laddoni H, Mohammadzadeh Hajipirloo H, Dinparast Djadid N, Hosseini A, et al. The Anopheles stephensi odorant binding protein 1 (AsteObp1) gene, a new molecular marker for biological forms diagnosis. Acta Trop. 2015;146:101-13.

5. Sharma V. Current scenario of malaria in India. Parassitologia. 1999:41:349-53.

6. Rowland M, Mohammed N, Rehman H, Hewitt S, Mendis C, Ahmad M, et al. Anopheline vectors and malaria transmission in eastern Afghanistan. Trans R Soc Trop Med Hyg. 2002;96:620-6.

7. Djadid ND, Gholizadeh S, Aghajari M, Zehi AH, Raeisi A, Zakeri S. Genetic analysis of rDNA-ITS2 and RAPD loci in field populations of the malaria vector, Anopheles stephensi (Diptera: Culicidae): implications for the control program in Iran. Acta Trop. 2006;97:65-74.

8. Azari-Hamidian S. Checklist of Iranian mosquitoes (Diptera: Culicidae). J Vector Ecol. 2007;32:235-42.

9. Ghosh SK, Tiwari S, Raghavendra K, Sathyanarayan TS, Dash AP. Observations on sporozoite detection in naturally infected sibling species of the Anopheles culicifacies complex and variant of Anopheles stephensi in India. J Biosci. 2008;33:333-6.

10. Manguin S, Carnevale P, Mouchet J, Coosemans M, Julvez J, Richard-Lenoble $\mathrm{D}$, et al. Biodiversity of malaria in the world. Montrouge: John Libbey Eurotext; 2008

11. Edrissian GH. Malaria in Iran: past and present situation. Iran J Parasitol. 2006:1:1-14.

12. Norouzinejad F, Ghaffari F, Raeisi A. Epidemiological status of malaria in Iran, 2011-2014. Asian Pac J Trop Med. 2016;9:1055-61.

13. WHO. World malaria report 2017. Geneva: World Health Organization; 2017.

14. Gholizadeh S, Djadid ND, Nouroozi B, Bekmohammadi M. Molecular phylogenetic analysis of Anopheles and Cellia subgenus anophelines (Diptera: Culicidae) in temperate and tropical regions of Iran. Acta Trop. 2013;126:63-74.

15. Romi R, Boccolini D, Di Luca M, La Rosa G, Marinucci M. Identification of the sibling species of the Anopheles maculipennis complex by heteroduplex analysis. Insect Mol Biol. 2000;9:509-13.

16. Djadid ND, Gholizadeh S, Tafsiri E, Romi R, Gordeev M, Zakeri S. Molecular identification of Palearctic members of Anopheles maculipennis in northern Iran. Malaria J. 2007:6:6.

17. Djadid ND. Molecular systematics of malaria vectors: studies based on RAPD PCR and related techniques. PhD Thesis, University of Liverpool: 1998.

18. Dassanayake RS, Gunawardene YI, Silva BD. ITS-2 secondary structures and phylogeny of Anopheles culicifacies species. Bioinformation. 2008;2:456-60.

19. Mehravaran A, Oshaghi MA, Vatandoost H, Abai MR, Ebrahimzadeh A, Roodi AM, et al. First report on Anopheles fluviatilis $U$ in southeastern Iran. Acta Trop. 2011;117:76-81.

20. Oshaghi MA, Yaghobi-Ershadi MR, Shemshad K, Pedram M, Amani H. The Anopheles superpictus complex: introduction of a new malaria vector complex in Iran. Bull Soc Pathol Exot. 2008;101:429-34.

21. Mayr E: Species concepts and definitions. In: Topics in the philosophy of biology. Berlin: Springer; 1976. p. 353-371.

22. Sweet W, Rao B, Rao A. Cross-breeding of An. stephensi type and An stephensi var. mysorensis. J Malar Inst India. 1938;1:149-54.

23. Suleman M. Intraspecific variation in the reproductive capacity of Anopheles stephensi (Diptera: Culicidae). J Med Entomol. 1990;27:819-28.

24. Rutledge LC, Ward RA, Bickley WE. Experimental hybridization of geographic strains of Anopheles stephensi (Diptera: Culicidae). Ann Entomol Soc Am. 1970;63:1024-30.

25. Oshaghi M, Yaghoobi F, Vatandoost H, Abai M, Akbarzadeh KJPJBS. Anopheles stephensi biological forms, geographical distribution, and malaria transmission in malarious regions in Iran. Pak J Biol Sci. 2006;9:294-8

26. Azari-Hamidian S, Harbach RE. Keys to the adult females and fourthinstar larvae of the mosquitoes of Iran (Diptera: Culicidae). Zootaxa. 2009;2078:1-33.

27. Sievers F, Higgins DG. Clustal Omega, accurate alignment of very large numbers of sequences. Methods Mol Biol. 2014;1079:105-16.

28. Tamura K, Peterson D, Peterson N, Stecher G, Nei M, Kumar S. MEGA5: molecular evolutionary genetics analysis using maximum likelihood, 
evolutionary distance, and maximum parsimony methods. Mol Biol Evol. 2011;28:2731-9

29. Sweet WC, Rao BA. Races of A. stephensi Liston. Indian Med Gaz. 1937;72:665-74.

30. Coluzzi M, Di Deco M, Cancrini G. Chromosomal inversions in Anopheles stephensi. Parassitologia. 1973;15:129-36.

31. Subbarao SK, Vasantha K, AdakT, Sharma VP, Curtis CF. Egg-float ridge number in Anopheles stephensi: ecological variation and genetic analysis. Med Vet Entomol. 1987;1:265-71.

32. Suguna SG. The genetics of three larval mutants in Anopheles stephensi. Indian J Med Res. 1981;73(Suppl):120-3.

33. Chen B, Butlin RK, Pedro PM, Wang XZ, Harbach RE. Molecular variation, systematics and distribution of the Anopheles fluviatilis complex in southern Asia. Med Vet Entomol. 2006;20:33-43.
34. Manonmani A, Townson H, Adeniran T, Jambulingam P, Sahu S, Vijayakumar T. rDNA-ITS2 polymerase chain reaction assay for the sibling species of Anopheles fluviatilis. Acta Trop. 2001;78:3-9.

35. Alam MT, Bora H, Das MK, Sharma YD. The type and mysorensis forms of the Anopheles stephensi (Diptera: Culicidae) in India exhibit identical ribosomal DNA ITS2 and domain-3 sequences. Parasitol Res. 2008;103:75-80.

36. Sedaghat MM, Linton YM, Oshaghi MA, Vatandoost H, Harbach RE. The Anopheles maculipennis complex (Diptera: Culicidae) in Iran: molecular characterization and recognition of a new species. Bull Entomol Res. 2003:93:527-35.
Ready to submit your research? Choose BMC and benefit from:

- fast, convenient online submission

- thorough peer review by experienced researchers in your field

- rapid publication on acceptance

- support for research data, including large and complex data types

- gold Open Access which fosters wider collaboration and increased citations

- maximum visibility for your research: over $100 \mathrm{M}$ website views per year

At BMC, research is always in progress.

Learn more biomedcentral.com/submissions 